\title{
METHODS OF POPULATION STUDY IN A BIOLOGY COURSE AT SCHOOL
}

(C) 2019

Lamekhov Yury Gennadyevich, doctor of biological sciences, professor of General Biology and Physiology Department

Lamekhova Elena Anatolyevna, candidate of pedagogical sciences, associate professor of General Biology and Physiology Department

South Ural State Humanitarian Pedagogical University (Chelyabinsk, Russian Federation)

Abstract. This paper discusses methods of population study in a Biology course at school based on characteristics of educational process organization at secondary and high school. The concept of «population», introduced in biology at the beginning of the XX century, was not immediately included in the school course, although at the moment it is used in the study of both private and general biological sciences. The connection of the concept content with genetics, ecology and synthetic theory of evolution is obvious. On the basis of this, there are different interpretations of the «population» concept, mutually complementing each other. The paper states that it is necessary to give correct examples of populations that should emphasize the state of isolation, duration of existence and the possibility of crossing between organisms within a population. The importance of using a schematic representation of populations and its examples is also noted. A schematic representation is a reflection of two basic variants of organism's distribution in the population and discussion of the role of these variants in the maintenance of the population existence. However, the considered subordination in the population is also important in ensuring the evolutionary process. The development of the population concept is based on the Hardy-Weinberg's law introduced in a Biology course at school, which until recently was only studied at the University course of Genetics. But full awareness of the population is possible only when considering this law, which characterizes the genetic structure of populations. The proposed approach is based on the ecological-evolutionary approach to the study of basic general biological concepts in school and University courses.

Keywords: methods of concepts study; general biological concepts; secondary school; high school; population; genetics; ecology; law; Hardy-Weinberg; schematic representation; evolutionary process; multidisciplinary approach; biological diversity; population of common pike; elementary evolutionary structure.

УДК 378.14

DOI 10.24411/2309-4370-2019-11310

Статья поступила в редакцию 20.01.2019

\section{ПЕДАГОГИЧЕСКИЕ ПУТИ РАЗВИТИЯ ПРОФЕССИОНАЛЬНОГО ОПЫТА ДЕЯТЕЛЬНОСТИ В КРИЗИСНЫХ СИТУАЦИЯХ У МАГИСТРАНТОВ ВОЕННОГО ВУЗА}

(C) 2019

Малашенко Леонид Иванович, старший научный сотрудник военного научно-исследовательского центра Национальный университет обороны имени Первого Президента Республики Казахстан (2. Астана, Республика Казахстан)

Аннотация. Актуализируется роль профессионального опыта в подготовке военных специалистов к деятельности в современных условиях, сопряжённых с возникновением и развитием кризисных ситуаций, пронизывающих фактически все сферы жизни общества. Совершенно очевидно, что без профессионально подготовленных, квалифицированных и опытных защитников немыслимо существование любого государства. Это повышает интерес к проблеме развития профессионального опыта офицеров как важного компонента готовности к эффективным действиям антикризисной направленности. В работе показаны методологические подходы к исследованию процесса развития опыта магистрантов - офицеров, обучающихся в военном вузе второго уровня высшего профессионального образования (магистратура). На основе анализа научных трудов в области подготовки военных кадров даётся определение профессиональной готовности военного специалиста. Рассмотрены отличительные особенности развития профессионального опыта офицера. В качестве решения обозначенной проблемы определены основные пути развития профессионального опыта деятельности в кризисных ситуациях у магистрантов военного вуза, в которых совмещается теория с практикой и исследовательской деятельностью, применение международного опыта и опыта ветеранов войн и военных конфликтов, педагогическая поддержка обучаемых с ценностным наполнением содержания образования, дифференциация обучения с особой позицией преподавательского состава, с проявлением особого внимания к формированию опыта у магистратов военного вуза.

Ключевые слова: профессиональный опыт; профессиональная деятельность; профессиональная готовность; профессиональная компетентность; этнокультурная компетентность; военно-профессиональное образование; профессионально-ценностная ориентация; кризисная ситуация; педагогический путь; педагогический поиск; исследовательский путь; интернациональный воинский коллектив; дифференцированный подход; позиция профессорско-преподавательского состава; миссия военного специалиста; магистрант военного вуза; национальный университет обороны; национальная безопасность; военная безопасность; коалиция государств; Организация Договора о коллективной безопасности.

Введение (постановка проблемы и цели исследования)

В современных условиях объективной кризисной реальности, когда ранее отлаженные механизмы за- щиты от потенциальных угроз повсеместно дают сбои, государства всё чаще объединяются в коалиции и решают вопросы обеспечения своей безопасности на коллективной основе. В России и Казах- 
стане, государствах, являющихся полноправными членами Организации Договора о коллективной безопасности, военно-профессиональное образование ориентируется на подготовку военных специалистов, способных эффективно выполнять многоплановые задачи в сфере обороны. В этой связи возрастает ценность обмена опытом профессионального обучения офицеров в военных вузах. В течение последних пяти-десяти лет многие военные учёные и специалисты: российские (В.А. Бородин [1, с. 21-119]; А.А. Дудоладов [2, с. 119-131]; Б.А. Карев [3, с. 250255]); А.И. Шишков [4, с. 24-146]; казахстанские (И.Н. Богданов [5, с. 57-62]; Р.Ф. Жаксылыков [6, с. 142-145]; А.А. Корнилов [7, с. 269-273]; А.Н. Рыспаев [8, с. 13-17]; К.С. Серикбаев [9, с. 90-93]; А.К. Тогусов [10, с. 94-99] и др.) исследовали названную проблему. Из анализа перечисленных и других изученных трудов следует, что весомым показателем качества профессиональной подготовки в области высшего военного образования реально выступает сформированный профессиональный опыт военного специалиста, позволяющий объективно воспринимать окружающую кризисную обстановку, системно и эффективно действовать в ней.

Важность развития профессионального опыта деятельности специалиста в образовании подтверждается и Федеральным законом «Об образовании в Российской Федерации», который определяет обучение «как целенаправленный процесс организации деятельности обучающихся по овладению знаниями, умениями, навыками и компетенцией, приобретению опыта деятельности, развитию способностей, приобретению опыта применения знаний в повседневной жизни и формированию у обучающихся мотивации получения образования в течение всей жизни» [11, ст. 2].

Продолжение современной реформы образования в Казахстане, отражённой в законе Республики Казахстан «Об образовании» [12, ст. 1, п. 41-2], государственных стандартах высшего образования [13], других правовых актах, обусловленное кардинальными политическими, экономическими, социокультурными трансформациями в мире и стране, вхождением Казахстана в Болонскую систему (2003 г.), связано и с повышением активности обучающихся, развитием самостоятельности и ответственности, мобильности и креативности в обучении, новыми требованиями к качеству профессиональной подготовки. Отмеченное выдвигает проблему развития профессионального опыта деятельности офицеров в кризисных условиях, соответствующих вызовам времени, на первый план. Целью исследования ставится определение педагогических путей развития профессионального опыта деятельности в кризисных ситуациях у магистрантов военного вуза.

\section{База и методика исследования}

В качестве ведущих применены системный, личностно-деятельностный и междисциплинарный методологические подходы, что позволило: исследовать процесс подготовки офицеров в военном вузе как систему, обеспечивающую развитие их профессионального опыта; изучать опыт определённого вида деятельности в кризисном антураже; анализировать развитие профессионального опыта офицеров в философском, психологическом, социологическом аспектах, интегрированных в аспекте педагогическом как системообразующем ядре.
Исследование проводилось на базе Национального университета обороны имени Первого Президента Республики Казахстан - Елбасы - ведущего военного вуза Казахстана [14].

Намеченные в ходе исследования педагогические пути развития профессионального опыта деятельности офицеров в кризисных ситуациях апробированы в двух экспериментальных группах, дифференцированных по уровням подготовки: 30 чел. - магистранты, обучающиеся по программе магистратуры (первый факультет), 25 чел. - по программе подготовки офицеров высшей квалификации (второй факультет).

Оценка профессионального опыта базируется на методике оценивания подготовки к деятельности в кризисных ситуациях, которая включает индивидуальную и групповую оценки.

$$
\begin{gathered}
C \Pi K \Phi^{I}=\frac{\sum M K \Phi^{l}}{K \Phi^{I}} \quad(1) ; \\
C \Pi K \Phi^{2}=\frac{\sum M K \Phi^{2}}{K \Phi^{2}} \quad(2) ; \\
C C \Pi=\frac{C \Pi K \Phi^{1}+C \Pi K \Phi^{2}}{K \Phi^{l}+K \Phi^{2}}
\end{gathered}
$$

Каждый магистрант оценивается индивидуально по всем элементам и суммарно согласно критериям оценки $-M$. Для групповой оценки используются экспериментальные группы: $K \Phi^{I}-$ группа первого факультета, $K \Phi^{2}$ - группа второго факультета. $C П-$ средний показатель в экспериментальных группах. ССП - суммарный средний показатель за обе экспериментальные группы.

Применение данной методики позволяет вывести оценку теоретической и практической подготовки участников эксперимента, которая становится основой определения уровня развития профессионального опыта офицеров (магистрантов военного вуза) при реализации показанных педагогических путей.

\section{Результаты и обсуждение}

Педагогический поиск путей развития опыта офицера изначально базировался на выявлении особенностей профессионального опыта как компонента готовности военного специалиста к выполнению обязанностей по обеспечению безопасности государства, защите его суверенитета и территориальной целостности.

Понятие «готовность» раскрывают многие исследователи.

И.М. Кондаков определяет готовность как форму установки на выполнение того или иного действия [15, с. 15]. Н.В. Кузьмина характеризует готовность к профессиональной деятельности наличием у специалиста знаний, умений и навыков, позволяющих ему осуществлять свою деятельность [16, с. 34]. Г.М. Андреева анализирует практическую готовность в концепции освоения коммуникативного умения, которая представляет собой комплекс освоенных коммуникативных действий, базирующихся на высокой теоретической и практической подготовленности личности $[17$, с. 43]. Т.И. Шалавина рассматривает готовность к профессиональной деятельности в виде индивидуализированного отражения действительности, выражающего отношение личности к объектам, ради которых развёртывается деятельность и общение [18, c. 90]. 
Профессиональную готовность военного специалиста можно определить как цель и конечный результат подготовки к профессиональной деятельности, систему взаимосвязанных между собой характеристик личности и субъективное её состояние, степень соответствия психологических и физических данных требованиям к качествам, необходимым для осуществления профессиональных функций. В настоящем исследовании профессиональная готовность офицера ориентируется на деятельность в кризисных ситуациях, требующую динамического целостного состояния, внутренней настроенности на сложность обстановки, мобилизации сил на активные и целесообразные действия по их разрешению. Готовность офицера к профессиональной деятельности обусловливается кризисной средой, в которой ему предстоит действовать, применяя на практике совокупность компетенций и опыта и доводя уровень своего профессионального опыта до высокого профессионализма.

Е.И. Рогов связывает профессионализм с компетенцией, определяя его как совокупность психофизиологических, психологических и личностных изменений, происходящих в педагогике в процессе овладения и длительного выполнения деятельности, обеспечивающих качественно новый, более эффективный уровень решения сложных профессиональных задач в особых условиях. Формирование профессионализма идет по трём направлениям: изменение системы деятельности, изменение личности субъекта, изменение компонентов установки субъекта по отношению к объекту деятельности [19, с. 4].

В.Н. Дружинин рассматривает профессионализацию как формирование специфических видов трудовой активности личности на основе развития совокупности его характеристик (рабочих, психологических, физиологических), обеспечивающих функцию регуляции становления и совершенствования субъекта труда. Согласно В.Н. Дружинину, профессионализация субъекта рассматривается в четырех аспектах: в ходе его социализации, в процессе развития личности, при самореализации индивида, как форму индивидуальной активности [20, с. 107-108].

Опираясь на положения, выдвинутые В.Н. Дружининым и Е.И. Роговым, процесс профессионализации военного специалиста можно рассматривать в четыре этапа:

- первый этап - получение начального опыта на основе первых жизненных впечатлений, которые в плане выбора профессии подлежат закреплению, как полезные, либо отклонению, как ненужные (в дошкольный и период начальной школы);

- второй этап - закрепление опыта, пополнение его свежими знаниями, новыми навыками, ориента- ция на определённые жизненные устои, патриотическое воспитание, начальная военная подготовка. Формирование в сознании некоторых молодых людей облика военной профессии;

- третий этап - профессиональный поиск, результатом которого становится выбор профессии, непосредственно связанной с защитой отечества, обеспечением военной безопасности;

- четвертый этап - освоение профессии, развитие профессионального опыта, социальная и профессиональная адаптация к условиям, в которых осуществляется деятельность.

Отличительные особенности развития профессионального опыта офицера нами структурируются по целям, задачам и результатам, а также по условиям, содержанию и технологии военно-профессиональной деятельности (рис. 1).

Обусловленность целей, задач и результатов развития профессионального опыта офицера рассматривается в разрезе его воинской службы, осуществления воинского труда и основывается на социальном заказе общества, закреплении его в нормативных правовых актах, в том числе в воинских уставах и наставлениях. Сочетание в выполняемых функциях многообразия составляющих опыта определяет полифункциональный характер военно-профессиональной деятельности.

Интегративный же характер результатов воинского труда складывается из показателей боеготовности и морально психологического состояния личного состава. Выдвигаемые цели и задачи опыта должны соответствовать профессиональным качествам специалиста, уровню его способности к решению профессиональных задач. Воинский труд не может представляться в виде шаблона, поскольку каждая реальная ситуационная задача неповторима, требует неординарного решения и подготовиться к ней следует в ориентировочно-прогностическом плане.

Особенности опыта деятельности офицера как составляющей его профессиональной компетентности по условиям, содержанию и технологии воинского труда отражаются в различных видах деятельности, классифицированных по социально-правовым, функциональным и другим, временно возникшим признакам, а также в личностном развитии военного специалиста и взаимоотношениях с коллегами по профессиональной работе. К таким особенностям следует отнести экстремальность условий выполнения профессиональных обязанностей, коллективный характер воинской службы и совместной деятельности военнослужащих, индивидуальное взаимодействие офицеров в процессе профессионального общения.

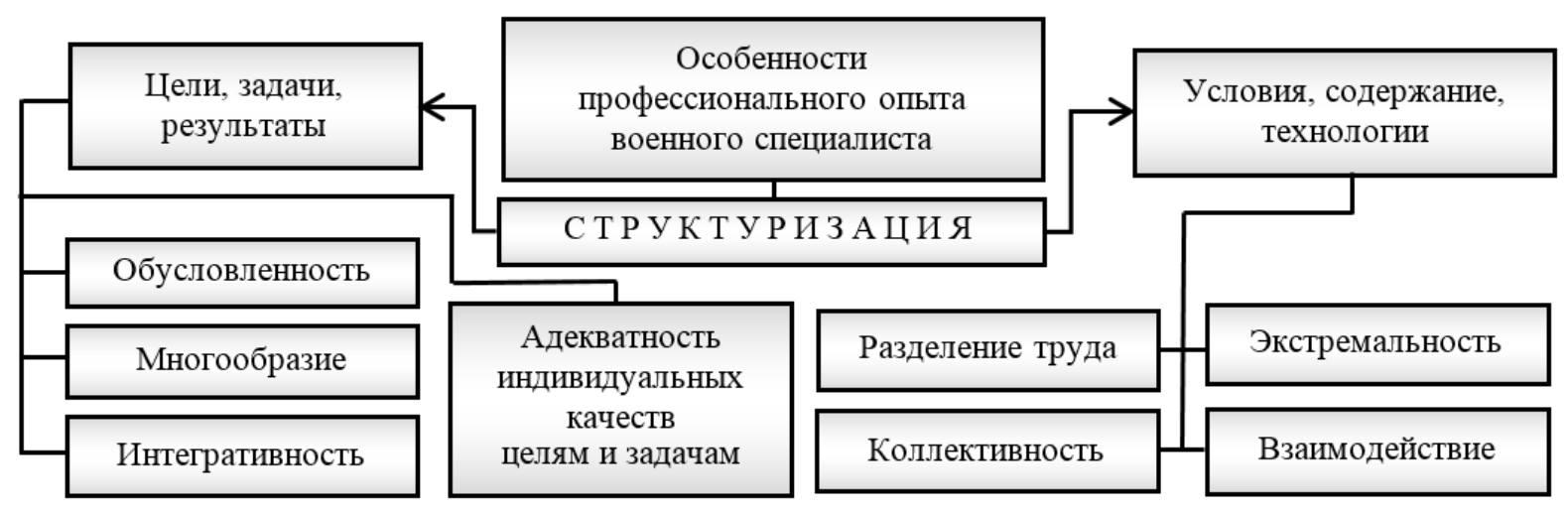

Рисунок 1 - Структуризация особенностей развития профессионального опыта военного специалиста 
В результате педагогического поиска намечены основные пути развития профессионального опыта деятельности в кризисных ситуациях у обучающихся офицеров (магистрантов военного вуза).

Первый путь - теоретический, являет собой базовую основу формирования опыта, в нём выделяется главная задача по отбору самого нужного и ценного из необъятного потока современной информации, а также по определению объёма знаний, умений и навыков, приобретаемых офицерами в процессе обучения и применяемых ими в дальнейшей профессиональной деятельности. Научный подход к формированию образовательного процесса становится важнейшим условием обеспечения качества подготовки офицеров в военных вузах. Офицер, получивший новую порцию знаний, чувствует прилив в своем профессиональном просвещении. Он изучил новые способы вооружённой борьбы, разрешения военного конфликта, кризисной ситуации. Уверенность офицера в своей готовности к действиям растет. Преподаватель, умудрённый собственным опытом, даёт офицеру для решения ситуационные задачи, которые следует решить с применением новой порции знаний. И в процессе решения задач военный специалист убеждается в важности теории для дальнейшей практической работы. Теоретически подкованный военный специалист «вооружён знаниями», он может не только принять решение на операцию, бой, боевые действия, но и обосновать свое решение, подкрепить его научными расчетами, аналитическими выводами. Теория - это источник, из которого можно черпать не только знания, но и опыт.

С опорой на теоретические знания показан второй путь - практический, представляемый как самый эффективный. История свидетельствует, что многие учёные шли к научным открытиям практическим путем, используя практический опыт своих исследований. Многие полководцы выигрывали сражения, применяя положительный опыт предыдущих побед и отрицательный опыт предыдущих поражений. Практика - лучшая база для применения теории. Не сильна практика без теории, равно как слаба и теория без практики. Получать практический опыт, опираясь на твёрдую теорию, значительно эффективнее, чем добывать его в ходе самой практики, как правило, методом проб и ошибок. В практическом опыте субъ- ект задействует не только зрительные и слуховые, но и эмоциональные, ассоциативные способы запоминания. В результате опыт, полученный практическим путем, когда стоит конкретная задача, которую нужно решить, закрепляется твёрже по сравнению с другими способами пополнения опыта. Следуя практическим путём, магистранты участвуют в командноштабных, тактических и других учениях различного масштаба, в ходе которых получают практику оценки обстановки, принятия и обоснования решений, проведения мероприятий по их реализации, организации операций, боевых и специальных действий по урегулированию кризисных ситуаций.

Третий путь - исследовательский (работа в составе исследовательских групп на мероприятиях оперативной и боевой подготовки, в том числе с коалиционными силами Организации Договора о коллективной безопасности), структурируется по составляющим, показанным на рис. 2.

Перцептивный компонент включает в себя: распознавание информационных признаков обстановки (ситуации), по которым офицер производит её оценку; образы, характеризующие ситуацию (состояние и действия противоборствующих сторон - противника и своих войск); актуализацию деятельности по разрешению ситуации. В ходе исследования военный специалист делает аналитические выводы о степени опасности обстановки, развитии ситуации, способах, применяемых силах и средствах её разрешения.

К семиотическому компоненту относятся методологические знания и умения, приобретаемые в исследовательской работе. Из совокупности методик обучения формам вооружённой борьбы, способам нормализации обстановки офицер выстраивает собственную методологию освоения новых нестандартных приёмов разрешения ситуации. В исследовании осуществляется непроизвольный интеллектуальный контроль, связанный с волевым самоконтролем субъекта. Офицер регулирует собственную импульсивность, способность к подавлению отрицательных эмоций, проявлений слабости, нерешительности. Формируется множество взглядов на ситуацию, подлежащую разрешению, восприятие возникающих задач, исходя из необходимости их выполнения по принципам: «никто кроме нас», «всё возможно - даже то, что невозможно».

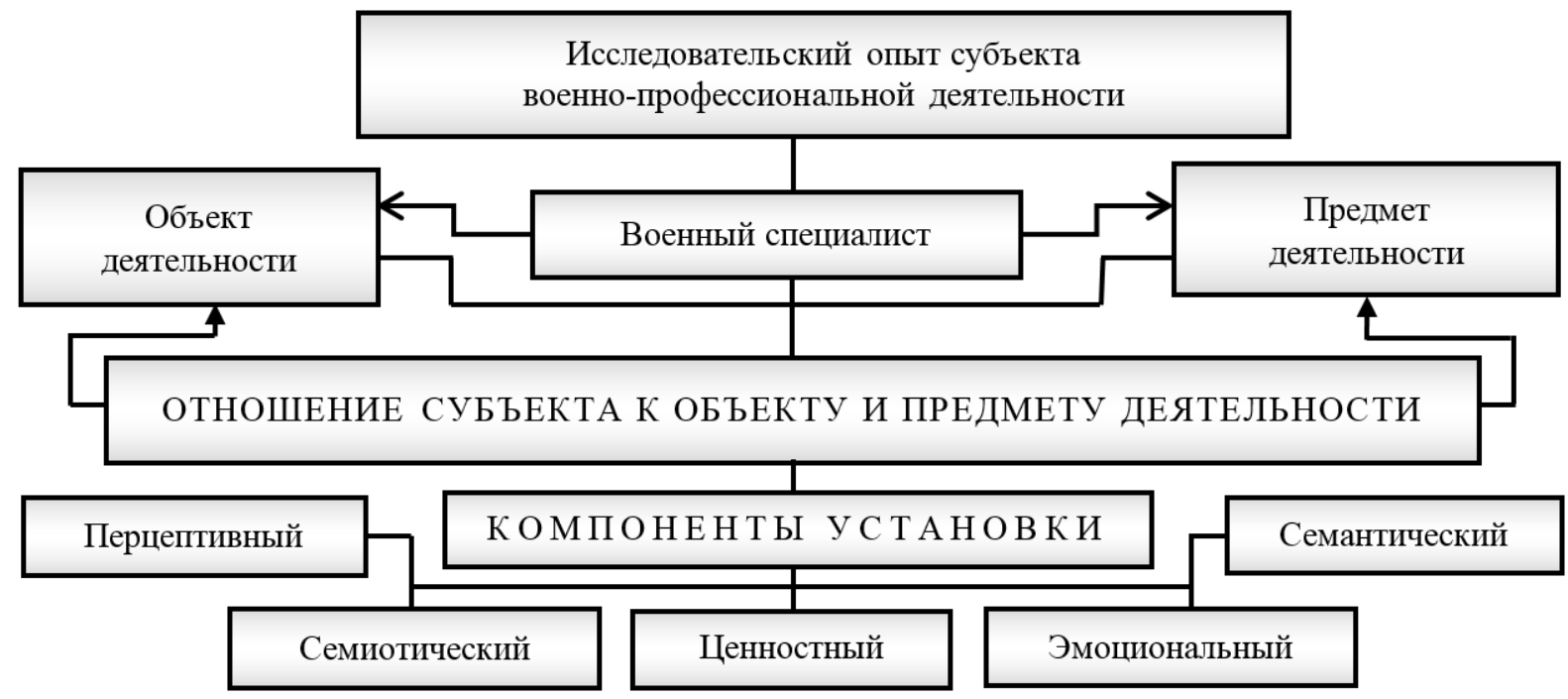

Рисунок 2 - Структуризация исследовательского пути развития профессионального опыта офицера 
В отличие от семиотических особенностей, в семантический компонент входит произвольный интеллектуальный контроль. Здесь военный специалист развивает способность прогнозировать, планировать и регулировать интеллектуальную деятельность, выбирает стратегию своего обучения. Познавательная позиция дополняется готовностью использовать разные способы анализа ситуаций и рефлексивным аспектом, который позволяет согласовывать деятельность с условиями её осуществления.

Эмоциональная составляющая основывается на ментальности опыта военного профессионала - его предпочтениях, убеждениях, умонастроениях. Сущность эмоциональной составляющей можно соотнести с психологическими механизмами опыта: познавательной потребностью, познавательным интересом, интеллектуальной активностью, опытом переживания интеллектуальных эмоций и чувств], а также с интуитивным опытом военного руководителя, который позволяет ему в определённой, конкретно заданной обстановке выбирать из множества вариантов единственно верный вариант действий.

Ценностный компонент исследовательского опыта базируется на ориентационных установках, направленных на: формирование у военного специалиста научного миропонимания; осознание специфики исследовательской деятельности; обозначение профессиональных ориентиров; представления о своих творческих возможностях и способностях к развитию критичности мышления и креативности деятельности.

Четвертый путь обозначается направленностью образовательного процесса на развитие профессионального опыта путём организации занятий и встреч магистрантов с офицерами и генералами, прошедшими «горячие точки», имеющими реальный опыт проведения операций по разрешению кризисных ситуаций. Опыт могут дать офицеру хорошие учителя, сослуживцы, начальники и подчиненные. Такой опыт дается либо в теории, либо в сочетании теории с практикой. Но лучшую школу даёт практик - человек, реально прошедший через собственный боевой (специальный) опыт, опыт войны, военных действий, специальных операций, опыт собственных побед. Не следует скептически относиться к философии чужих побед. Такая философия оправдана практикой, подтверждённой успехами. Такая философия заслуживает внимания. О чужих победах можно и нужно рассуждать, - это обогащает собственные представления о практических действиях. Такая наука помогает мыслить и анализировать. Здесь, по сравнению с лекциями об учениях давно забытых классиков и мудрёных определений, например о законах боя, наступлении и обороне, более ценными представляются рассказы реальных участников боевых действий в так называемых «горячих точках». Полезным является опыт генералов и офицеров, участвовавших в операциях на территории Афганистана, Чечни, Ирака, Сирии, др. Преподнесённые уроки хороши, когда знания, полученные от них, можно в перспективе применить и проверить на практике. Тогда и только тогда они смогут генерировать, пополнить профессиональный опыт.

Четвертый путь направлен к ценностному наполнению содержания образования дополнительным материалом для изучения офицерами, обучающимися в магистратуре военного вуза. Материал включает положения по военной дипломатии, искусству разрешения современных военных конфликтов в кризисных условиях. Освоение магистрантами новых дисциплин, отражающих вопросы дипломатического искусства и управления войсками коалиционного состава, будет оказывать положительное влияние на готовность выпускников военных вузов к урегулированию кризисных ситуаций и укреплению системы коллективной безопасности.

Пятый путь выражает педагогическую поддержку магистрантов в овладении навыками дипломатического искусства: ведения диалога на международном уровне, критического мышления, анализа чужого мнения с учётом различной государственной, этнической и религиозной принадлежности. Здесь важной составляющей профессиональной компетентности выступает компетентность этнокультурная, отражающая способность офицера к восприятию и реализации идеи поликультуры и уважительного отношения ко всем этническим единицам при управлении интернациональным воинским коллективом. При этом важно изучать и использовать международный опыт разрешения военных конфликтов, проведения антикризисных операций. Чужой опыт можно перенять, можно принять частично, можно отвергнуть, как ненужный. Бытует мнение, что нужно изучать только работы профессионалов. В этом есть свой резон: из опыта профессионала можно извлечь полезные уроки. Однако полезным может стать и, как правило, становится опыт конкурентов, в исследуемом аспекте - опыт противника, представителей противоположной, враждебной стороны. Здесь отмечается три момента: во-первых, поиск ошибок поднимает самооценку офицера; во-вторых, в результате поиска можно найти оригинальные подходы, которые по ряду причин не имели положительного эффекта; в-третьих, результаты чужого опыта могут дать немало полезной информации, позволяющей военному специалисту пополнить свой собственный профессиональный опыт.

Шестой путь отражает дифференцированный подход к развитию профессионального опыта офицера в ходе обучения в военном вузе. Дифференциацию в научно-теоретическом толковании можно квалифицировать как результат научного поиска путей повышения качества образовательного процесса высшей военной школы. Она призвана формировать у военных специалистов гибкие, мобильные, многофункциональные знания, опытные навыки, с помощью которых они смогут на высоком уровне решать профессиональные задачи. Дифференциация приводит к достижению разнообразия в образовании, что является залогом его стабильности, обеспечивает возможность выбора эффективных образовательных технологий. Такой подход представляется актуальным в педагогике подготовки военного профессионала.

Седьмой путь способствует утверждению особой позиции профессорско-преподавательского состава, характеризующейся вниманием к развитию профессионального опыта деятельности в кризисных ситуациях у офицеров в ходе их обучения в магистратуре военного вуза. Рассматриваемая позиция - это устойчивая система отношений преподавателя к определённым сторонам действительности (умение обучае- 
мых вести переговоры, достигать результата операции не силовым, а дипломатическим путём, управлять интернациональными коллективами).

\section{Выводы}

1. Реализация предложенных путей развития профессионального опыта у магистрантов военного вуза при соблюдении соответствующей профессионально-ценностной ориентации создаёт благоприятные педагогические возможности для формирования готовности офицеров к профессиональной деятельности в современных кризисных условиях.

2. Ценность профессионального опыта позволяет офицеру осознавать возможности и границы своей компетентности и определяется соответствием опыта миссии военного специалиста по защите общества от современных угроз его безопасности.

3. Уверенность офицера в своей профессиональной готовности подтверждается наличием приобретённых компетенций и сформированного профессионального опыта, подкрепляется исследовательской и практической работой, в ходе которой он осваивает знания, воплощает их в принимаемых решениях и выполняемых действиях по их реализации.

\section{Заключение}

Подготовка опытных военных профессионалов, обладающих способностями к оценке военно-политической обстановки, выявлению очагов международной напряженности, к планированию и проведению операций по разрешению кризисных ситуаций и организации борьбы с терроризмом в различных его проявлениях - задача непростая, но вполне выполнимая в системе высшего военного профессионального образования. У таких офицеров есть широкое поле деятельности для сохранения мира, развития теории и практики применения коалиционных сил, управления ими и взаимодействия на всех уровнях в целях обеспечения национальной безопасности своего государства и коллективной безопасности стран членов коалиции.

\section{Список литературы:}

1. Бородин В.А. Подготовка курсантов военных вузов к морально-психологическому обеспечению личного состава подразделений сухопутных войск: дис. ... канд. пед. наук. М., 2017. 240 с.

2. Дудоладов А.А. Формирование самостоятельного творческого мышления выпускников военных образовательных организаций высшего образования МО РФ: проблема и пути её решения // Вестник Сибирского отделения Академии военных наук. 2017. № 45. С. 119-131.

3. Карев Б.А., Литвинова Н.Б., Петрушин И.Е. Образовательная модель как основа технологии профессиональной подготовки в военном вузе // Право и практика: научный журнал НИИ истории, экономики и права. 2017. № 3. С. 250-255.

4. Шишков А.И. Формирование профессиональной компетентности курсантов военных вузов в ходе тактико-специальной подготовки: дис. ... канд. пед. наук. М., 2014. 278 с.

5. Богданов И.Н. Подготовка кадров для Военноморских сил Республики Казахстан // Военно-теоретический журнал «Ориентир» Министерства обороны Республики Казахстан. 2018. № 1 (77). С. 57-62.
6. Жаксылыков Р.Ф. Система педагогических условий для качественной военно-профессиональной подготовки офицеров Национальной гвардии Казахстана // Теория и практика общественного развития. Краснодар: Хорс, 2015. С. 142-145.

7. Корнилов А.А. О развитии военной науки и военного образования в контексте выполнения служебно-боевых задач национальной гвардией // Национальный университет обороны имени Первого Президента Республики Казахстан - Лидера Нации флагман военного образования и военной науки Республики Казахстан: сборник материалов междунар. теоретической конф. Астана: РИО НУО РК, 2017. C. 269-273.

8. Рыспаев А.Н. Подход к выбору показателей эффективности функционирования системы обеспечения офицерскими кадрами // Научный журнал «Сардар» Центра военно-стратегических исследований Республики Казахстан. 2015. № 2 (27). С. 13-17.

9. Серикбаев К.С. Профессиональная армия: пути подготовки воина-профессионала // Вестник Академии военных наук Республики Казахстан. 2014. № 1. C. $90-93$.

10. Тогусов А.К., Тогусова А.К. Подготовка военных кадров в рамках Организации Договора о коллективной безопасности // Всестороннее обеспечение коалиционной группировки войск (сил) при подготовке и ведении совместных операций (боевых действий): сборник материалов междунар. военно-науч. конф. Астана: РИО НУО РК, 2016. С. 94-99.

11. Федеральный закон от 29.12.2012 № 273-Ф3 «Об образовании в Российской Федерации» [Электронный ресурс] // Государственная система правовой информации. Официальный интернет-портал правовой информации. - http://pravo.gov.ru/proxy/ips/? docbody $=\&$ link_id $=6 \&$ nd $=102162745$.

12. Об образовании: Закон Республики Казахстан от 27 июля 2007 г. № 501-V // Ведомости Парламента Республики Казахстан, 2007. С. 2-94.

13. Постановление Правительства Республики Казахстан от 23 августа 2012 года № 1080 «Об утверждении государственных общеобязательных стандартов образования». 338 с.

14. Жасузаков С.А. Кузница военных кадров высшей военной квалификации // Военно-патриотический журнал «Айбын». 2013. № 6 (64). С. 3-8.

15. Кондаков И.М. Психологический словарь. М.: Фаир-Пресс, 2000. 488 с.

16. Кузьмина Н.В. Педагогическая психология: учебное пособие. СПб.: Издательство В.А. Михайлова, 2008. 209 c.

17. Андреева Г.М. Социальная психология: учебник для высших учебных заведений. М.: Изд-во Форум, НИЦ Инфра-М, 2013. 192 с.

18. Шалавина Т.И., Канторович Н.Я., Попова Г.Н. Формирование профессионально значимых качеств будущего учителя на этапе допрофессиональной подготовки: учебно-методическое пособие. Новокузнецк: РИО КузГПА, 2002. 121 с.

19. Рогов Е.И. Учитель как объект психологического исследования: пособие для психологов по работе с учителем и педагогическим коллективом. М.: Изд. центр ВЛАДОС, 1999. 996 с.

20. Дружинин В.Н. Психология: учебник для гуманитарных вузов. СПб.: Питер, 2009. 407 с. 


\title{
PEDAGOGICAL WAYS OF MILITARY UNIVERSITY STUDENTS' PROFESSIONAL EXPERIENCE DEVELOPMENT IN CRISIS SITUATIONS
}

(C) 2019

\author{
Malashenko Leonid Ivanovich, senior researcher of Military Research Center \\ National Defense University named after the First President of the Republic of Kazakhstan \\ (Astana, Republic of Kazakhstan)
}

\begin{abstract}
The paper deals with the role of professional experience in training military specialists to work in modern conditions, associated with the emergence and development of crisis situations that permeate virtually all spheres of society. It is obvious that the existence of any state is unthinkable without professionally trained, qualified and experienced defenders. This increases interest in the development of professional experience of officers as an important component of the readiness for effective action of anti-crisis orientation. The paper shows methodological approaches to the study of the process of military university master's experience development. The author proposes a definition of a military specialist professional readiness on the basis of scientific works analysis. The author also considers distinctive features of the officer's professional experience development. The author defines the main ways of professional experience development in crisis situations for military university undergraduates. They combine theory with practice and research activities, the use of international experience and experience of veterans of wars and military conflicts, pedagogical support of students with the value content of education, differentiation of training with a special position of the teaching staff, with special attention to military university students' professional experience development.

Keywords: professional experience; professional activity; professional readiness; professional competence; ethnocultural competence; military-professional education; professional-value orientation; crisis situation; pedagogical way; pedagogical search; research way; international military collective; differentiated approach; position of teaching staff; mission of military specialist; master student of military higher education institution; national university of defense; national security; military security; coalition of states; collective security treaty organization.
\end{abstract}

\section{УДК 37.02}

DOI 10.24411/2309-4370-2019-11311

Статья поступила в редакцию 09.11.2018

\section{ПОНЯТИЕ О РУССКОМ МИРЕ ПРИ ФОРМИРОВАНИИ СОЦИОКУЛЬТУРНОЙ КОМПЕТЕНЦИИ У ИНОСТРАННЫХ СТУДЕНТОВ}

(C) 2019

Марчук Светлана Владимировна, аспирант кафедры общей педагогики, истории педагогики и образования; преподаватель кафедры русского языка Ленинградский государственный университет им. А.С. Пушкина (2. Санкт-Петербург, Российская Федерация); Военно-морская академия им. Адмирала Флота Советского Союза Н.Г. Кузнецова (2. Санкт-Петербург, Российская Федерации)

Аннотация. Автором проводится анализ понятия Русский мир, ставшего устойчивым оборотом не только в России, но и за рубежом. Предлагается обоснование понятия Русский мир в историческом, педагогическом, психологическом и философском аспектах. Автор статьи интерпретирует основной смысл этого понятия для освоения традиций Русского мира иностранными студентами, изучающими русский язык как иностранный. Статья нацелена на формирование социокультурных компетенций иностранных студентов благодаря верному преподнесению понятия Русский мир. Предлагается обоснование концепции понятия Русский мир и возможные приёмы обучения. Автор уверен, что на преподавателя возлагается ответственность верно преподносить информацию обучающимся. Значит, обучение иностранных студентов в общем и частном зависит от подготовленности преподавателя: его идеологии, знаний и методики преподавания. Особенно важно, на взгляд автора, изучение предложенной темы в настоящее время.

Ключевые слова: коммуникативная компетенция; социокультурная компетенция; понятие; понятие Русский мир; русская идея; традиции; русская диаспора; этнос; культура; концепция; лингвострановедение; фонд «Русский мир»; учебный сайт; мультимедийные технологии; информационная культура; интернетресурсы.

Формирование коммуникативных компетенций при обучении русскому языку иностранцев является основополагающим, потому что компетентность характеризует уровень владения языком и включает в себя лингвистическую, речевую и коммуникативную компетенции.

Следует отметить, что коммуникативная компетенция включает в себя социокультурную, которая подразумевает знание изучающими иностранный язык национально-культурных особенностей социального и речевого поведения носителей языка (их обычаев, этических норм, социальных и культурных стереотипов, знаковых моментов истории и культуры), а также умение пользоваться этими знаниями в процессе общения [1].

В социокультурную компетенцию входят прежде всего знания, связанные со сведениями о стране изучаемого языка, духовных ценностях и культурных 